\title{
Searching for a "black sky" in the Andes Mountains: A migratory process and identity formation of a Japanese astronomer in Peru
}

\author{
Naoko Kato-Nitta \\ School of Advanced Sciences, The Graduate University for Advanced Studies(SOKENDAI) \\ Shonan-Village, Hayama, Kanagawa 240-0193, Japan \\ email: kato_naoko@soken.ac.jp
}

\begin{abstract}
This paper examines the transnational migratory process and identity formation of a Japanese astronomer, Mutsumi Ishitkuta (born 1930). He moved to Peru in 1957 to build a solar observatory in the Andes Mountains, and settled there to develop a foundation for basic sciences in Peru. Through life story interviews, I explore the transnational migratory process of this scientist focusing on his profession in relationship to certain people, events, and situations that contributed to his identity formation. Tracing Ishitsuka's story may enable us to deepen our thoughts of scientists' identity and their role for the society.
\end{abstract}

Keywords. Peruvian astronomy, transnational migration, Japan-Peru astronomical collaboration

\section{Introduction}

Why do humans migrate? This question has long been addressed by the field of social sciences especially in the areas of social history, area studies, and urban sociology. (Massey et al., 1993). In Japan, these studies have explored in depth the conditions of Japanese emigrants or immigrants and their experiences. However, previous works center on a specific stratum of workers and have not well covered the phenomena at the opposite end of the migration spectrum; scientists and other highly skilled professionals.

Recently researchers dealing with international labor mobility and demographic shifts were keen on these issues as typified by the "brain drain" phenomena. Generally speaking, these studies focus on demographical quantization or the direction of the movements from relatively low-income countries to higher-income countries with favorable conditions mainly based on push-pull factors. However, it is considered difficult to estimate the number of highly educated migrants because they are generally short-term workers and not assumed to be an additional burden to recipient countries (Stalker 2000). As Kajita (2005) points out, today's ongoing human mobility is extremely multiple-vectored and complex. Thus, comprehending this phenomenon only via economical or state policy constraints seems rather insufficient. Two factors deserve notice here. First concerns a migrant's decision to cross national borders responding to their structural environments. In the current situation, these decisions originate not by coercion, political conflicts or even strong inducement provided by the recipient nations. This suggests that diversification of personal orientation or values may lead to variety of individual transnational migratory processes in particular social contexts. Secondly, if highly-skilled professionals are presumably more motivated to keep their professional identity and seek involvements for their profession, then these types of psychological incentives may deliver greater effect on their migratory decisions than economic motives. Understanding how migratory processes are related to one's individual life course and cumulative biographical narratives 
may provide some hints to deepen our perspectives on broader patterns of migratory decision making (Brettell 2003).

Among my study subjects on Japanese scientists who have migrated, astronomer Mutsumi Ishitsuka's career appears one of the most compelling. I came to know his career in 2005 through his son, José Ishitkuta, who was born and raised in Peru by Ishitsuka and his wife, Ayako, a native of Japan. Then he was about to return to Peru to promote Peruvian astronomy after obtain ing his $\mathrm{Ph}$.D. in radio astronomy from Tokyo University. Jose told me about the story of his father and their transnational mobility. This experience initiated me to ask of many questions: (1) Why did these astronomers migrate to this place, not to the frontline of their field? (2) What factors did they prioritize other than economic concerns in their migratory processes? (3) What was the driving force of the father to stir his enthusiasm toward development of Peruvian astronomy in spite of the terrible destruction of the observatory by anti-government guerillas? (4) What was the meaning for them to persuade low-income Peruvian people to understand the importance of the basic sciences despite having their hands full with daily life? An opportunity to interview Mutsumi Ishitsuka was finally realized in 2008 following "the International Workshop on New Astronomical Facilities in Peru - in honor to Mutsumi Ishitsuka", held by Instituto Geofísico del Perú (IGP), Peru, from June 28 to July 8th. His career suggests a strong motivation and ardor as an astronomer towards serving science under tenuous conditions.

Although what prompted me to conduct interviews with Mutsumi Ishitsuka stemmed from a sociological perspective, I introduce his adventurous career to address certain issues concerning the identity of migrant scientists and their role in the society.

\section{Mutsumi Ishitsuka's life story}

Mutsumi Ishitsuka, a former director of the Ancon Observatory of the Instituto Geofísico del Perú (IGP), is a Japanese astronomer living in Lima, Peru. He was born on January 5th, 1930 at Hankou, China. His family had established links with China beginning from his grandfather's generation. His father studied applied chemistry at a technical high school in Osaka and went to Hankou to operate a wood oil refinery. When the SinoJapanese War broke out in 1937, his family decided to return to Japan in response to an evacuation order issued by the Japanese Consulate. On his way back to the relative's house, Ishitsuka experienced the triggering event of interest toward astronomy he himself recalls. During his brief stay at Osaka, he visited the Osaka Municipal Denki-Kagaku Museum, the forerunner of Osaka Science Museum. There he had a chance to experience the first planetarium installed in Japan. Later in his life, he devoted his effort to establish the first public planetarium facility in Lima, Peru. Lima was said to be the last capital city in the world that did not have a planetarium facility before the installation of the National Planetarium in 2008 within the IGP headquarters. Ishitsuka emphasizes importance of scientific educational facility like planetarium, especially for the children living under overcast weather conditions like Lima.

Ishitsuka migrated to Peru in 1957 as a research student of the Department of Astronomy, Kyoto University. The purpose of his move from Kyoto University to Instituto Geofísico del Perú (IGP) was to fulfill the plan of installing a coronagraph telescope in the Andes Mountains. This plan was initiated in 1937, when a group of astronomers including Issei Yamamoto and Masazou Horii from Kyoto University visited Peru to observe a total solar eclipse. These astronomers were fascinated by the beyond-blue, blackish sky they saw in the Andes and soon formulated a plan to install a coronagraph there. Astronomers from Tokyo University had already started observations of solar corona from 
1951 at the Norikura Solar Observatory which was established in 1949. Horii from Kyoto University wrote a note in the "Uchu-Kai newsletter" that expressed enthusiasm for the plan of installing coronagraph in Peru showing an intimate sense of rivalry with Tokyo University (Horii 1998).

Tokyo University has already started a solar corona observation at the top of Norikura Mountain. They are struggling against the adverse conditions there. They are using a 5303 angstrom filter. We will easily record the 5303 wave in the Andes Mountains and our observational records will reveal the reality of solar corona. we will do it under the blackish blue sky in the Andes.

\subsection{In search of a black-sky in the Andes Mountains}

However, this collaborative plan between Japan and Peru had to surmount procedural constraints. First, it was shelved due to the World War II. Subsequently, it was suspended twice due to budgetary shortfall in Japan. At that time, it was almost impossible to transfer such an expensive national asset beyond Japan, so they had to find alternate own resources. Joe UEDA, a professor of the Department of astronomy, Kyoto University, spent a personal fortune to build a coronagraph to be transferred to Peru. When this plan appeared in the newspaper in 1951, many Japanese citizens donated money for it. In 1951, only four countries (USA, Switzerland, France, and Japan) had solar observatory with a coronagraph (Suematsu 2001) . If they could install a coronagraph in the Andes, Peru, then it would become the first coronagraph installed in the southern hemisphere. And most of all, it would be the coronagraph to be in the highest altitude and best atmospheric condition ever. This plan captivated not only solar physicists of Kyoto University but also many Japanese citizens.

The third problem was that the plan was drastically delayed by incomplete preparations to receive the telescope in Peru. "Day after day, I walked around the Andes Mountains here and there in search of a black sky." Ishitsuka recalled his days of a hard work, searching for the ideal place to install a coronagraph.

\subsection{Being a Japanese astronomer in Peru}

During World War II, many Japanese Peruvians were sent by the Peruvian government to internment camps in the United States (Yanagida and Yoshii, 1999). Considering the time of Ishitsuka's migration in the late 1950's, still in the aftermath of the war, the social conditions of Peru as a victor nation and Japan as a vanquished were apparently different. His purpose and interest of migrating to Peru was to observe solar flares from an ideal location. However, the existence of Japanese Peruvian community strongly made him aware of his national identity.

There is something important I must give an account before telling you about building the observatory. First of all, I noticed that bringing a coronagraph from Japan and installing it in Peru meant such a great deal. My original thought was that I thought I was in Peru for a scientific purpose, but my job became "Accomplish the work for Japan, or Japanese residents in Peru cannot stay in this country any longer."

It was thought that they were trying to make an inappropriate donation.

On the other hand, Ishitsuka's presence at Huancayo Observatory, located 3000m above sea level in the Andes, brought "two cultures" closer. Before their arrival, Japanese 
Peruvians living in Huancayo had no chance to visit the IGP Huancayo observatory. They were grateful that the observatory became closer due to Ishitsuka's presence. They showed him a sense of respect by helping him and his family in everyday life.

\subsection{Delight, despair and hope}

After nine years of struggle, the ceremony for completion of the coronagraph delivery from Japan to Peru was held on September 25, 1966. Ishitsuka recalled this day as the best day of his life.

The ceremony was the single most significant event that dominated my life. This is because I devoted myself to bringing the telescope from Japan to Peru since I came here on July 3rd, 195\%. I dedicated my life to it. I pondered that I would even die for it.

He finally managed to establish the Cosmos Observatory in the Andes and installed the coronagraph in 1978, more than twenty years had passed since his settlement in Peru. The biggest hardship occurred in October 1988, not long after he fully started solar corona observations in July of 1988. In 1988, because of the failure of Peruvian governmental activities, public safety deteriorated. Inflation spiraled. The anti-government guerillas increasingly expanded their range from Huancayo to the surrounding regions, especially on the route to Lima. Unfortunately, the Cosmos Observatory was located on that path. Then, the fear came when the guerillas occupied the Cosmos Observatory. They asked for the infrared scope Ishitsuka had.

"No, No. If I give it to them, they will use it to snipe. Many governmental key people would get shot. So, I will never give it to them." After two or three days passed, people around me said: "Just give them binoculars. Let them have binoculars and let them go." Then, "If I do, I am telling a lie."

While all of this was going on, one week passed, and the guerrillas just exploded the observatory. Why didn't he opt to return to Japan? He answered:

Of course, I thought about going back to Japan, but I stayed because the head of IGP asked me to. He beseeched me to stay.

It was the time when the astronomer from Japan felt that he was fully admitted his competence as a scientist and trust in this country.

\section{Concluding remarks}

In 2008, "the International Workshop on New Astronomical Facilities in Peru - in honor to Mutsumi Ishitsuka" was held by the Instituto Geofísico del Perú (IGP), Peru, from June 28 to July 8th. Most of the eleven invited speakers of the workshop were senior Japanese astronomers who have been formally and informally encouraged and helped Ishitsuka's work. Other participants were Peruvian IGP staffs and students from several Peruvian universities.

In the middle of the desert near the city of Ica, Mutsumi Ishitsuka and his son, Jose, and researchers in Ica University were collaboratively planning to establish an educational astronomical observatory. While the workshop was being held, a groundbreaking ceremony for the educational observatory took place in June 29, 2008. Due to schedule delays, the ceremony was held in the freezing desert night rather than in the sunny daytime. Takehiko Kuroda, the head of the Nishi-Harima Astronomical Observatory raised 
about twenty million yen in funds towards donating a telescope to install in this educational observatory. The telescope is about to be completed. Nevertheless, the identified site has not yet started constructing the building. The situation surrounding basic sciences in this country has not been much developed since Ishitsuka migrated fifty years ago. However, there is always a hope such that presence of many young students from Ica University dreaming of becoming an astronomer, representative of Japanese Peruvian Community in Ica, and the participants of the workshop from Japan and Peru all toasting with a pisco sour in this candidate site for the observatory. It is hoped that this observatory will be completed and many Peruvian children and students will gather here to observe the sun.

To sum up Ishitsuka's career appears as an extreme case. Clearly, one must exercise caution in making generalizations from a specific case. However, I infer that Mutsumi Ishitsukafs career presents a distinctive opportunity to explore transnational migratory process of scientists and identity. First, our understanding of this process will be significantly facilitated by exploring the conflicts between his professional identity as an astronomer and his national identity as a Japanese (Ishitsuka et al. 2006) . This conflict existed under circumstances not just a different cultural context but also life-threatening conditions. This extremeness of his case provides a contrast to the basic qualities of his role as a scientist. Secondly, his experiences at various life stages in multiple cultural contexts (youth, adolescence, adulthood and maturity) are noteworthy. Therefore, an examination of how his identify as a scientist formed during these different life-stages provide richness to our understanding. Ishitsuka did experience the best day of his life in Peru and accomplished his role as a Japanese-Peruvian astronomer.

The Peruvian State Minister for the environment in his speech, delivered at the first public presentation of National Planetarium in Lima and commented: "I want to express my cordial apologies for the destruction of the Cosmos Observatory on behalf of all the Peruvian people." Referring this comment, Ishitsuka noted "If he says so, let's forget about it. Forget it." What's notable about Ishitsuka's identity was that it is not symbolized by nationality or economic, material structures. He established his identity in Peru, by devoting himself to astronomy that none could achieve until now.

\section{Acknowledgements}

I thank Dr. Shin-ya Nitta and Dr. Makoto Miyoshi, two astronomers for their role as accompanying interviewers. Dr. Nitta in particular joined this project from its early stage and I appreciate his contribution for producing fruitful in-depth interviews. I also thank all the participants for "the International Workshop on New Astronomical Facilities in Peru: In honor to Mutsumi Ishitsuka". I appreciate the help of Dr. Satoru Ikeuchi, Dr. Kazunari Shibata, Dr. Jun Kubota and Dr. Yoshio Tomita for their contribution in providing historical documents about astronomy in Kyoto University. I also thank Dr. Sachi Sri Kantha for a critical reading of this text. This fieldwork in Peru was supported by the research grant, "Oral History of Big Sciences" directed by Dr. Kohji Hirata, from the Japan Society for the Promotion of Science [JSPS]. Last but not least, I thank the Ishitsuka family members for their cooperation in the fieldwork and interviews.

\section{Note}

As the interviews and investigations were conducted in the Japanese language, the quotations were translated into English by the author. 


\section{References}

Brettell, C. 2003, Anthropology and Migration: Essays on Transnationalism, Ethnicity, and Identity (New York: Altamira Press), p. 24

Horii, M. 1998, in: Kyoto University Uchu-Kai Newsletter, Vol. 13

Ishitsuka, J. et al. 2007, in IAU Special Session 5, Astronomy for the Developing World, J.B.Hearnshaw and P. Martinez (eds) (Cambridge: Cambridge University Press), p. 77

Kajita, T. 2005, Transnational/Global Sociology (Nagoya: Nagoya University Press)

Massey, D.S., et al. 1993, Population and Development Review, 19, 431

Stalker, P. 2000, Workers Without Frontiers: The Impact of Globalization on International Migration (Boulder and London: International Labour Organisation and Lynne Rienner Publishers)

Suematsu, Y. 2001, Coronagraphs in the World http://solarww.mtk.nao.ac.jp/en/ coronagraphs.html

Yanagida, T. and Yoshii, Y. 1999, Japanese Peruvians in Twentieth Century: Life Stories and Portraits of One Hundred People (Tokyo: Fuyo Syobo) 